\title{
Detection of future changes in trends and scaling exponents in extreme short-term rainfall at selected stations in Slovakia
}

\author{
Silvia KOHNOVÁ ${ }^{1}$, Marianna VASILAKI ${ }^{2}$, Martin HANEL ${ }^{3}$, \\ Ján SZOLGAY ${ }^{1}$, Kamila HLAVČOVÁ ${ }^{1}$, Athanasios LOUKAS², \\ Gabriel FÖLDES ${ }^{1}$ \\ ${ }^{1}$ Slovak University of Technology in Bratislava, Faculty of Civil Engineering, \\ Department of Land and Water Resources Management, \\ Radlinského 11, 81005 Bratislava, Slovakia; \\ e-mail: silvia.kohnova@stuba.sk, jan.szolgay@stuba.sk, kamila.hlavcova@stuba.sk, \\ gabriel.foldes@stuba.sk \\ ${ }^{2}$ Laboratory of Hydrology and Aquatic Systems Analysis, \\ Department of Civil Engineering, University of Thessally, \\ PedionAreos, 38334 Volos, Greece \\ ${ }^{3}$ Czech University of Life Sciences Prague, Faculty of Environmental Science, \\ Kamýcká 129, 16500 Prague 6 - Suchdol, Czech Republic
}

\begin{abstract}
This paper analyses projected changes in short-term rainfall events during the warm season (April-October) in an ensemble of 30 regional climate model (RCM) simulations. The analysis of trend changes and changes in scaling exponents was done for the Hurbanovo, Bratislava, Oravská Lesná, and Myjava stations in Slovakia. The characteristics of maximum rainfall events were analysed for two scenario periods, one past and one future (1960-2000 and 2070-2100) and compared to the characteristics of the actual observed events. The main findings from the analysis show that 60 -min shortterm events for most of the RCM simulations will either increase or remain constant. On the other hand, the depths and intensities of daily events are projected to increase significantly; in some cases they were found to be ten times larger. Trends in future events at the Hurbanovo station were found to be insignificant. In the other stations positive trends in future rainfall events prevail, except for daily rainfall at the Myjava station, which shows a negative trend. Using results from the selected simulations, the scaling exponents estimated are on average lower than the exponents of the data observed. On the other hand, due to the higher daily precipitation amounts in the future seen to all the scenarios, the downscaled values of short-term rainfall at all the stations analysed might be considerably higher in the future horizons, which could subsequently affect future design rainfall values for engineering designs.
\end{abstract}

Key words: trend analysis, scaling exponents, short-term rainfall, RCM projections 


\section{Introduction}

Changes in precipitation will be one of the most critical factors determining the overall impact of climate change. There is evidence that regions that are already wet are likely to get wetter, but details on how much wetter and what impacts there will be on a local scale are difficult to ascertain. The dry regions of the subtropics are likely to get drier and will shift towards the poles. For much of Europe, wetter winters are expected, but drier summers are anticipated over central and southern Europe. It is likely that in a warmer climate, heavy rainfall will increase and be produced by fewer but more intense events. This could lead to longer dry spells and a higher risk of floods.

The detection of trends in precipitation data is also an essential point for the assessment of changes in the water resources of a region and the impacts from climate variability. Testing the significance of the trends observed in hydrological and climatic time series has received a great deal of attention recently, especially after changes observed in the natural and human environments due to global warming. This is reflected by the huge number of studies carried out over the last three decades dealing with assessments of the significance of trends in a variety of natural time series, including temperature, evaporation, precipitation, flow, and water quality time series $(I P C C, 2007)$. Several studies have analyzed extreme precipitation trends across Europe. Madsen et al. (2014) provided a review of the trend analysis of extreme precipitation and hydrological floods in Europe based on observations and future climate projections. They found that there is evidence of a general increase in extreme precipitation, whereas there are no clear indications of significant trends on large-scale regional or national levels of extreme streamflow. For Slovakia, Hlavcova et al. (2015) estimated the impact of climate change-induced extreme precipitation events on flooding. An increase in extreme 5-day precipitation totals and floods was indicated.

Another useful tool in water resources management is knowledge of the quantiles of extreme precipitation of various durations. Such information is usually expressed as the relationship between the intensity-duration-frequency (IDF) of extreme rainfall. The IDF relationship of heavy storms is one of the most important hydrological tools used by engineers for designing flood alleviation and drainage structures in urban areas. Local IDF equations 
are often estimated on the basis of records of intensities abstracted from rainfall depths of different durations that have been observed at a given rainfall gauging station. In some regions, there may exist a number of rainfall gauging stations operating for a time period sufficiently long enough to yield a reliable estimation of the IDF relationships; in many other regions, especially in developing countries, these stations are either non-existent or their sample sizes are too small. Because daily precipitation data is the most accessible and abundant source of rainfall information, it seems natural, at least for regions where data at higher time resolutions are scarce, to develop and apply methods to derive the IDF characteristics of shortduration events from daily rainfall statistics.

The scaling hypothesis is a method that is able to use daily rainfall statistics in order to derive characteristics for shorter duration rainfall events, which has been the main topic of several studies during recent decades. In these studies scaling formulas were proposed to extend the IDF relationship from the usual daily time scale to shorter durations based on the scaling properties of the rainfall. Koutsoyiannis and Foulfoula-Georgiu (1993) used a scaling model to predict storm hyetographs. Menabde et al. (1999) showed that based on the empirically observed scaling properties of rainfall and some general assumptions about the cumulative distribution function for the annual maxima of mean rainfall intensity, it is possible to derive simple IDF relationships. In Slovakia the scaling properties of extreme rainfall were tested in the studies of Bara et al. (2009). The authors examined the scaling properties of extreme rainfall in Slovakia in order to establish the scaling behavior of statistical moments over different durations.

The purpose of this paper is to analyze changes in extreme short-term precipitation event characteristics at four stations in Slovakia, i.e., Myjava, Bratislava, Hurbanovo and Oravská Lesná. The analysis was performed during the warm period (April-October) since the most extreme rainfall events occur in Slovakia during this period. The data used were the annual maxima rainfall values of the warm period, which were obtained by an ensemble of Regional Climate Models (RCM) within the ENSEMBLES (van der Linden and Mitchell, 2009) and EURO-CORDEX (Jacob et al., 2014) projects. The event characteristics were analyzed for two scenario periods, i.e., one past and one future (1960-2000 and 2070-2100). Historical data observed at a one-minute time step resolution were also used, so that we 
could evaluate the results of the models due to future changes. Trends in the projected events were estimated and compared with the characteristics of the historical events. The scaling properties of the projected events were examined so as to estimate the scaling exponents of the future data. This paper is a follow up of a previous study, i.e., Vasilaki et al. (2017), which examined changes in the seasonality of the short-term rainfall at these stations.

The paper is organized as follows: A theoretical description of the climate models used is provided in the following section. The methodology section describes the methods used to estimate the trend and scaling exponents of short-term rainfall. The study area and data sets used are described in section 3. The exposition of the results follows in the respective section. The paper is closed by a discussion and summary.

\section{Methodology}

\subsection{Trend detection}

In a number of studies parametric and non-parametric tests have been applied for trend detection. Both types of tests are commonly used; the parametric tests are more powerful, but they require data to be normally distributed and independent. On the other hand, non-parametric tests can deal with outliers within the data sets as they only require that the data be independent.

The non-parametric Mann-Kendall test (Mann, 1945; Kendall, 1955) is one of the most widely-used tests for detecting trends in a time series. It is based on testing the correlation of two groups of observations as proposed by Kendall (1955) and takes into account the correlation between the rank order of the values observed and their order over time. The null hypothesis is that the data are independent and randomly ordered, i.e., that there is no serial correlation or trend among the observations.

However, observations in time series are often autocorrelated. Simulation studies reveal that a positive autocorrelation makes it too easy to assert a significant trend, while a negative autocorrelation makes it too difficult to find a significant trend. Cox and Stuart (1955) stated that "positive serial correlation among the observations would increase the chance of significant 
error, even in the absence of a trend". Since most series in practice exhibit a positive autocorrelation, this makes it important to check the autocorrelation in a given series and adjust the test if necessary. In this paper, the modified Mann-Kendall test proposed by Hamed and Rao (1998) was applied to take into account the possible presence of autocorrelation in our data.

The rank correlation test (Kendall, 1955) for two sets of observations $X=x_{1}, x_{2}, \ldots, x_{n}$ and $Y=y_{1}, y_{2}, \ldots, y_{n}$ is constructed as follows. The statistic $\mathrm{S}$ is calculated as follows:

$S=\sum_{i<j} a_{i j} b_{i j}$,

where

$a_{i j}=\operatorname{sgn}\left(x_{j}-x_{i}\right)=\left\{\begin{array}{rl}1 & x_{i}<x_{j} \\ 0 & x_{i}=x_{j} \\ -1 & x_{i}>x_{j}\end{array}\right.$,

and $b_{i j}$ is similarly defined for the observations in Y. Under the hypothesis of independent and normally ordered data, the statistic S tends to normality for large $\mathrm{n}$, with the mean and variance given by:

$E(S)=0$.

$\operatorname{Var}(S)=n(n-1)(2 n+5) / 18$.

If the $\mathrm{Y}$ values are replaced by the order of the time series $\mathrm{X}$, the test can be used as a trend test. In this case, the statistic becomes:

$S=\sum_{i<j} a_{i j}=\sum_{i<j} \operatorname{sgn}\left(x_{j}-x_{i}\right)$,

with the same mean and variance. Kendall (1955) gives a proof of the asymptotic normality of the statistic $S$. The significance of trends is tested by comparing the standardized test statistic $Z=S /[\operatorname{var}(S)]^{0.5}$ with the standard normal variate at the desired significance level.

However, when the data are autocorrelated, the variance $S$ depends on the true autocorrelation structure, which in practice is unknown. Hamed and Rao (1998) propose an approximation. First, they calculate the Sen's 
slope and then subtract the predicted values from the data, which is an attempt to make the series stationary. Then, the autocorrelations of the ranks of the resulting data are calculated. These are then used in calculating an approximate variance of $S$, which is larger if the series is positively autocorrelated. An "effective sample size", i.e., $n_{S}^{*}$ is obtained. When the data are positively autocorrelated, $n / n_{S}^{*}$ is greater than 1 , and when the data are negatively autocorrelated, $n / n_{S}^{*}$ is less than 1 . If there is no autocorrelation, the ratio is equal to 1 , and no adjustment is made. The variance of $S$ is multiplied by the factor $n / n_{S}^{*}$ in the test for the significance of $S$.

In this paper the existence and significance of trends were examined for both the past and future scenario periods and for the observed data, using the modified Mann-Kendall trend test in order to avoid delusive results due to the possible existence of autocorrelation within the data. Then comparative boxplots were constructed, in order to detect the changes in behaviour between the past and future events, as well as the differences among the stations and rainfall durations. In addition to the detection of trends during the whole time period, the moving trends and rainfall duration were also estimated for each station in order to perceive the evolution and the yearly distribution of the intense short-term rainfall and detect in trends changes points.

\subsection{The simple scaling methodology}

In this study, a simple scaling hypothesis was adopted in order to derive the IDF characteristics of the rainfall. The methodology applied herein follows the one used in Menabde et al. (1999) and Yu et al. (2004). For detailed information on the theoretical background of the multifractal behavior of rainfall, the reader is referred to Veneziano and Furcolo (2002), and Lovejoy and Schertzer (1995), more practice-oriented results can be found, e.g., in Gupta and Waymire (1990), Menabde et al. (1999), Yu et al. (2004), and Molnar and Burlando (2008).

Let $I d$ and $I \lambda d$ denote the annual maximum rainfall intensity series for the time durations $d$ and $\lambda d$, respectively. The two random variables $I d$ and $I \lambda d$ are related through the scale factor $\lambda$ (which is the ratio between the two time durations) and have the same scaling property as (Yu et al., 2004): 
$I_{\lambda d} \stackrel{\text { dist }}{=} \Lambda^{\beta} I_{d}$,

where the equality is meant in the sense of the equality of the probability distributions of both variables, and $\beta$ represents the scaling exponent. Such a behaviour is denoted as "simple scaling in the strict sense" (Gupta and Waymire, 1990).

This type of scaling implies that both variables have the same probability distribution function if the finite moments of an order $q$ exist for both. The relationship between the $q^{\text {th }}$ moments of rainfall intensity can be obtained after raising both sides of Eq. (1) to power $q$ and taking the ensembles average (Yu et al., 2004):

$E\left[I_{\lambda d}^{q}\right]=\lambda^{\beta_{q}} E\left[I_{d}^{q}\right]$,

where $\beta q$ represents the scaling exponent of order $q$. The scaling exponent can be estimated from the slope of the linear regression relationships between the log-transformed values of the moments and the scale exponents for the various orders of moments. The case where the relationship between the scaling exponent and order of moment is linear is referred to as "wide sense simple scaling" (Gupta and Waymire, 1990).

The scaling behavior can also be found for the parameters of a fitted cumulative distribution function (CDF) if the CDF has a standardized form (Menabde et al., 1999; Yu et al., 2004):

$F_{d}(i)=F\left(\frac{i-\mu_{d}}{\sigma_{d}}\right)$,

where function $F$ is independent of $d$. For the simple scaling process it can be shown that the statistical properties of the CDF for the two different timescales $d$ and $\lambda d$ are related as follows (Menabde et al., 1999; Yu et al., 2004):

$\mu_{\lambda d}=\lambda^{\beta} \mu_{d}$,

and

$\sigma_{\lambda d}=\lambda^{\beta} \sigma_{d}$,

where $\mu d(\sigma d)$ is the location (scale) parameter of the annual precipitation maxima of duration $d ; \lambda$ denotes the scale factor; and $\beta$ is the scaling 
exponent. Based on these assumptions, the intensities $I_{d}^{P}$ of events with the same annual frequency $P$, but a different duration $d$, will satisfy the scaling relation

$I_{\lambda d}^{P}=\lambda^{\beta} I_{d}^{P}$

On the basis of Eq. (10), it is possible to estimate the scaling exponent even if the data record is short (Menabde et al., 1999).

\subsection{Regional Climate Models}

Regional Climate Models (RCMs) are widely used for the dynamic downscaling of Global Climate Model (GCM) simulations in order to bridge the gap between the relatively coarse resolution of GCMs (hundreds of $\mathrm{km}^{2}$ ) and typical scales needed for impact studies and adequate representations of regional heterogeneity such as complex orography, land cover or land/water contrasts. RCM simulations provide high-resolution (tens of square kilometers) information that is consistent with a GCM-simulated (large-scale) climate (Rummukainen, 2010). Fine spatial scales provided by RCMs are especially important for precipitation, near-surface wind speeds, and key atmospheric processes, particularly those controlling the development of highimpact weather events. Information about the RCMs used in the present study is provided in the data section.

\section{Study area}

Slovakia is located in a mild climate zone with precipitation influenced by the Atlantic Ocean that impacts predominantly in the western part of the country; the continental influence is typical of the southeastern part. The Mediterranean climate mainly influences the southern part of central Slovakia with higher precipitation totals in the autumn.

The Sixth National Communication of the Slovak Republic on Climate Change (2013) for the period of 1880-2012 showed that a significant increase in the mean annual air temperature of $1.8^{\circ} \mathrm{C}$ and an insignificant decrease in the annual areal precipitation totals by about $1.3 \%$ was recorded. The developments in temperature and precipitation were accompanied by a decrease 
in relative air humidity and an increase in potential evapotranspiration by about 5\% in southern Slovakia. The period of 1880-2012 was significant not only for the rapid increase in air temperature (by about $2{ }^{\circ} \mathrm{C}$ ) but also for the great variability in precipitation totals ( $164 \%$ of the normal in $2010,74 \%$ of the normal in 2003), which caused several episodes of serious drought on the one hand and local or regional floods on the other. The changes in the winter precipitation totals and the increase in the winter air temperature caused unstable snow conditions in Slovakia, but an increase in snow cover days and depths was recorded only in the higher mountains.

\subsection{Data analysis}

The measured rainfall data of the hourly time steps from the warm season (April-October) were provided by the Slovak Hydrometeorological Institute for the Myjava, Oravská Lesná, Bratislava and Hurbanovo climatological stations. The locations of the stations are presented in Fig. 1, and the basic information of the analyzed stations are presented in Table 1 . The stations were selected due to the availability of the climate scenarios provided by the Czech University of Life Sciences Prague (Dr. Hanel) and also to cover the southern, northern and western parts of Slovakia, which have the longest actual observation periods of short-term rainfalls. The annual maxima rain-

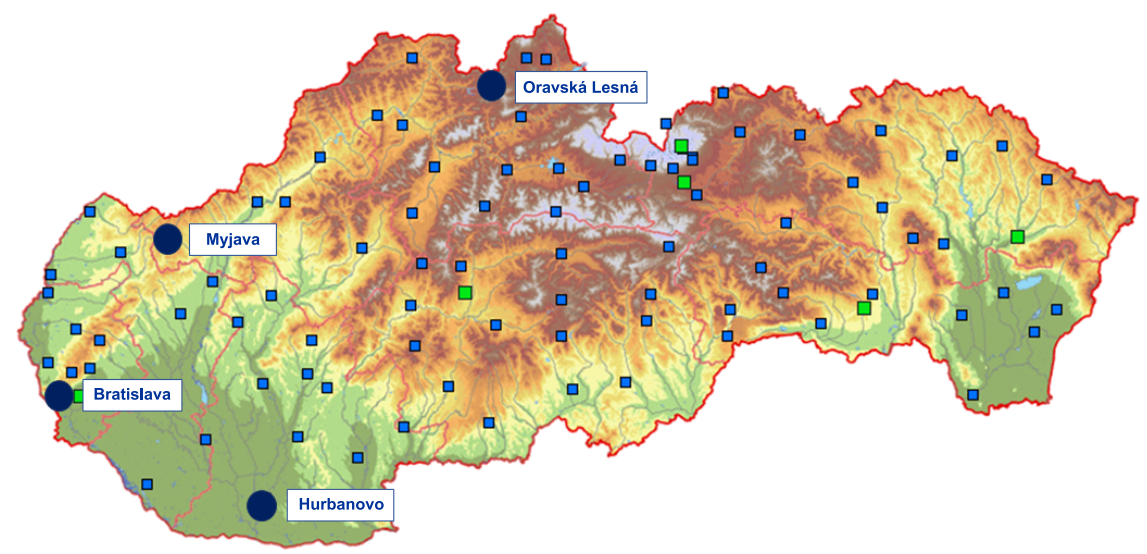

Fig. 1. The network of climatological stations in Slovakia with the locations of the analyzed stations. 
fall for various durations from 60 up to $1440 \mathrm{~min}$. were determined from the hourly rainfall time series measurements. For the Hurbanovo station, the observation period ranged from 1961 to 1994, while for the other stations it was from 1995 to 2009.

Table 1. Basic information about analyzed stations.

\begin{tabular}{|l|c|r|r|r|r|r|r|r|}
\hline $\begin{array}{l}\text { Climatological } \\
\text { Station }\end{array}$ & $\begin{array}{l}\text { Elevation } \\
\text { [a.s.1.] }\end{array}$ & \multicolumn{3}{|c|}{ Latitude } & \multicolumn{3}{|c|}{ Longitude } & $\begin{array}{l}\text { 100-year daily pre- } \\
\text { cipitation [mm] }\end{array}$ \\
\hline \hline Bratislava & 287 & 48 & 10 & 7 & 17 & 6 & 38 & 82.6 \\
\hline Myjava & 349 & 48 & 45 & 14 & 17 & 33 & 42 & 72.9 \\
\hline Oravská Lesná & 780 & 49 & 22 & 6 & 19 & 10 & 59 & 130.0 \\
\hline Hurbanovo & 115 & 47 & 52 & 23 & 18 & 11 & 39 & 77.0 \\
\hline
\end{tabular}

In the present study we considered an ensemble of $30 \mathrm{RCM}$ simulations (see Table 2) of 3 RCMs conducted within the ENSEMBLES (van der Linden and Mitchell, 2009) and CORDEX (Jacob et al., 2014) projects in hourly

Table 2. Overview of the RCM simulations applied.

\begin{tabular}{|c|c|c|c|c|c|}
\hline RCM & Driven by GCM & Project & Forcing & $\begin{array}{l}\text { Temp } \\
\text { Res } \\
\end{array}$ & Spat Res \\
\hline \multicolumn{6}{|c|}{ HadRM3.0 (Collins et al., 2011) - Met Office Hadley Centre (MOHC), UK } \\
\hline HadRM3Q0_HadCM3 & HadCM3Q0 & ENSEMBLES & SRES A1B & $1 \mathrm{~h}$ & $25 \mathrm{~km}$ \\
\hline HadRM3Q3_HadCM3 & HadCM3Q3 & ENSEMBLES & SRES A1B & $1 \mathrm{~h}$ & $25 \mathrm{~km}$ \\
\hline HadRM3Q16_HadCM3 & HadCM3Q16 & ENSEMBLES & SRES A1B & $1 \mathrm{~h}$ & $25 \mathrm{~km}$ \\
\hline
\end{tabular}

RCA4.0 (Kupiainen et al., 2011; Samuelsson et al., 2011) - Swedish Meteorological and Hydrological Institute (SMHI)

\begin{tabular}{llllll}
\hline RCA4_CanESM2 & CCCMaCanESM2 & EUR-44 CORDEX & RCP4.5, RCP8.5 & $20 \mathrm{~min}$ & $50 \mathrm{~km}$ \\
RCA4_CNRMCM5 & CNRM-CM5 & EUR-44 CORDEX & RCP4.5, RCP8.6 & $20 \mathrm{~min}$ & $50 \mathrm{~km}$ \\
RCA4_EC-EARTH & ICHEC-EC-EARTH & EUR-44 CORDEX & RCP2.6, RCP4.5, RCP8.5 & $20 \mathrm{~min}$ & $50 \mathrm{~km}$ \\
RCA4_CM5AMR & IPSL-CM5A-MR & EUR-44 CORDEX & RCP4.5, RCP8.5 & $18 \mathrm{~min}$ & $50 \mathrm{~km}$ \\
RCA4_MIROC5 & MIROC5 & EUR-44 CORDEX & RCP4.5, RCP8.5 & $20 \mathrm{~min}$ & $50 \mathrm{~km}$ \\
RCA4_HadGEM2ES & MOHC-HadGEM2-ES & EUR-44 CORDEX & RCP4.5, RCP8.5 & $20 \mathrm{~min}$ & $50 \mathrm{~km}$ \\
RCA4_ESMLR & MPIESM-LR & EUR-44 CORDEX & RCP4.5, RCP8.5 & $20 \mathrm{~min}$ & $50 \mathrm{~km}$ \\
RCA4_NorESM1M & NCC-NorESM1-M & EUR-44 CORDEX & RCP4.5, RCP8.5 & $20 \mathrm{~min}$ & $50 \mathrm{~km}$ \\
RCA4_ESM2M & NOAAGFDL-ESM2M & EUR-44 CORDEX & RCP4.5, RCP8.5 & $20 \mathrm{~min}$ & $50 \mathrm{~km}$
\end{tabular}

RACMO2.1 (van Meijgaard et al., 2008) - Royal Netherlands Meteorological Institute (KNMI)

\begin{tabular}{|c|c|c|c|c|c|}
\hline RACMO2_ECHAM5 & ECHAM5-r3 & ENSEMBLES & SRES A1B & $1 \mathrm{~h}$ & $25 \mathrm{~km}$ \\
\hline RACMO2_MIROC & MIROC3.2 & ENSEMBLES & SRES A1B & $1 \mathrm{~h}$ & $25 \mathrm{~km}$ \\
\hline
\end{tabular}


time steps. The simulations are on a rotated longitude-latitude grid with a horizontal resolution ranging from $12 \times 12 \mathrm{~km}$ (RACMO_22E simulations) to $50 \times 50 \mathrm{~km}$ (RCA4 simulations). The simulations were driven by $10 \mathrm{GCMs}$ under SRES A1B, RCP2.6, RCP4.5 and RCP8.5 forcing. Time series of annual maximum short-term precipitation for the past (1960-2000) and future (2070-2100) periods from grid boxes covering the climatological stations selected were considered.

To select the most appropriate scenarios for the stations selected, we contacted the climatologist prof. M. Lapin and Dr. M. Gera from the Department of Astronomy, Physics of the Earth and Meteorology, Faculty of Mathematics, Physics \& Informatics, Comenius University, Bratislava, Slovakia. The final models suggested are the ones highlighted in Table 2.

First, we analyzed the values of the average intensities of the projected 60-min rainfall. The results at the Hurbanovo station are presented in Fig. 2 and compared with the average observed results, which are represented by a red line. We can see that the mean projected intensities are either almost equal to the observed values or higher, except for the projections of the RACMO2 models, which are significantly smaller. Another feature is in Fig. 3, where there is a comparison of the average daily intensities with the

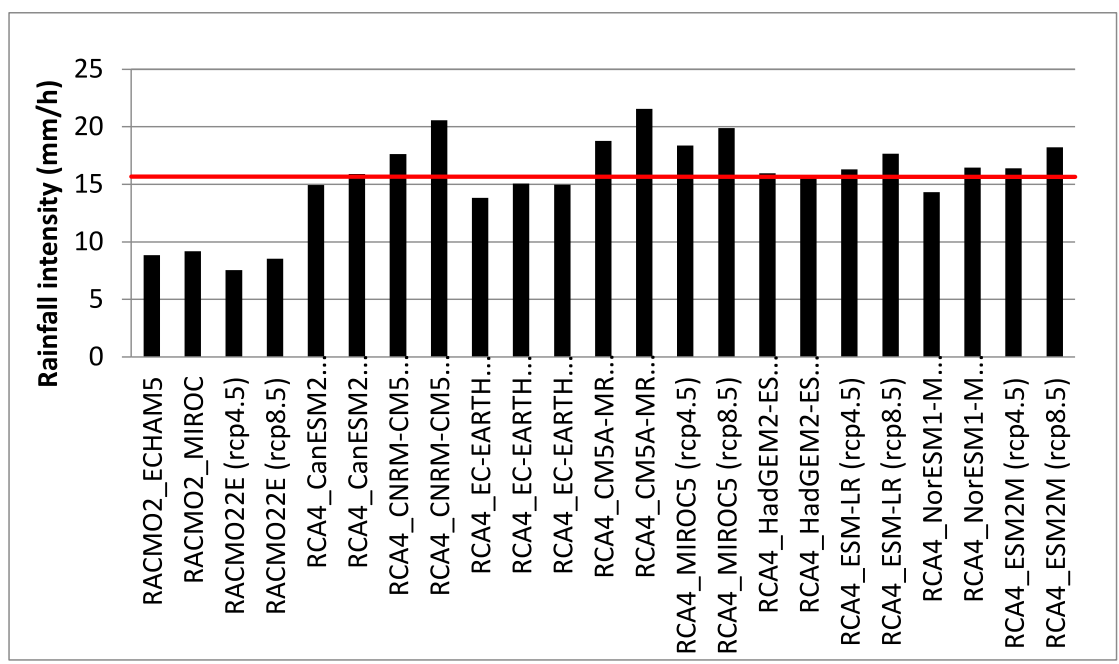

Fig. 2. Comparison of the projected 60-min rainfall intensities with the ones observed at the Hurbanovo station. 


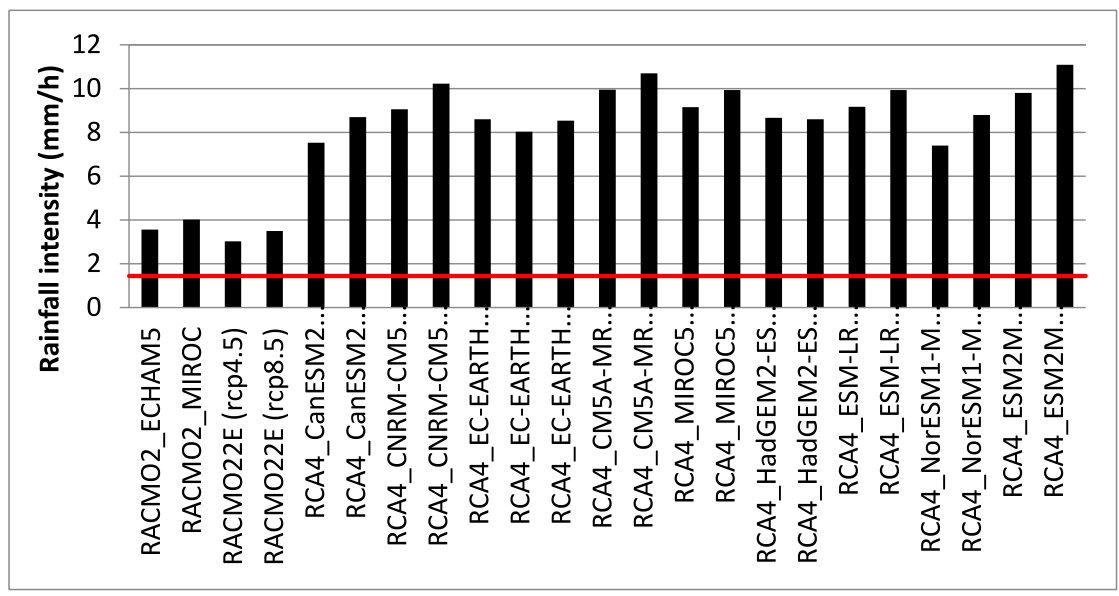

Fig. 3. Comparison of the projected daily rainfall intensities with the ones observed at the Hurbanovo station.

ones observed. All the daily rainfall projected intensities are significantly higher than the observed ones for all the stations. Similar results were also confirmed for the rest of the stations.

\section{Results}

As described in the methodology section, the modified Mann-Kendall trend test was applied to detect trends in the data. The significance level of the test was taken as equal to $5 \%$. The first step was to estimate the trends using the results of all the simulations. The significant trends detected at the Myjava, Bratislava and Oravská Lesná stations are presented in the form of boxplots in Figs. 4-6, respectively. The orange box stand for the future events, while the grey one (or, in some cases, a line Fig. 6. Trends in precipitation events at the Oravská Lesná (2070-2100) with a smaller width) represents trends detected in the past events. Trends detected at the Hurbanovo station were insignificant. We can observe from the Figures that at all the stations and for all the rainfall durations, positive trends prevail, except for the daily rainfall at the Myjava station, which has a negative tendency. The range of the boxes is in some cases broader. This is due to the contradictory results of the different simulations. 


\section{Myjava}

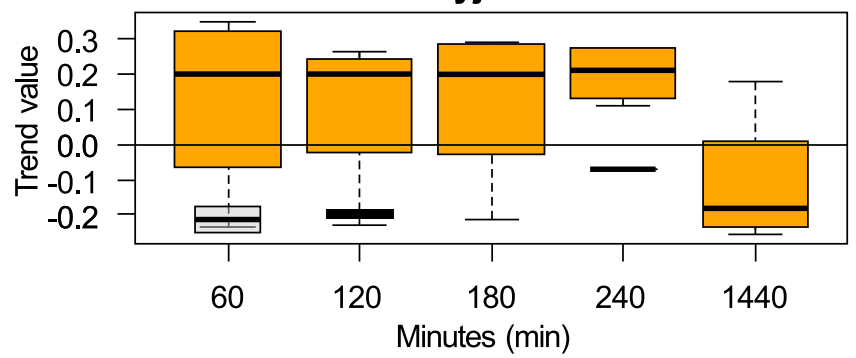

Fig. 4. Trends in precipitation events at the Myjava station (2070-2100).

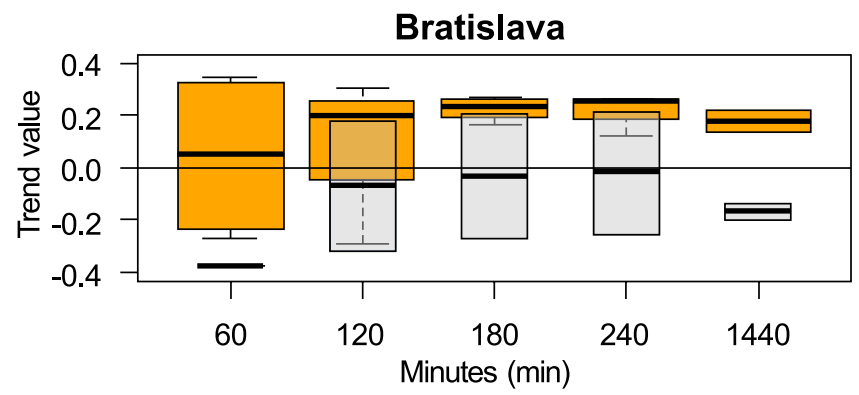

Fig. 5. Trends in precipitation events at the Bratislava station (2070-2100).

\section{Oravská Lesná}

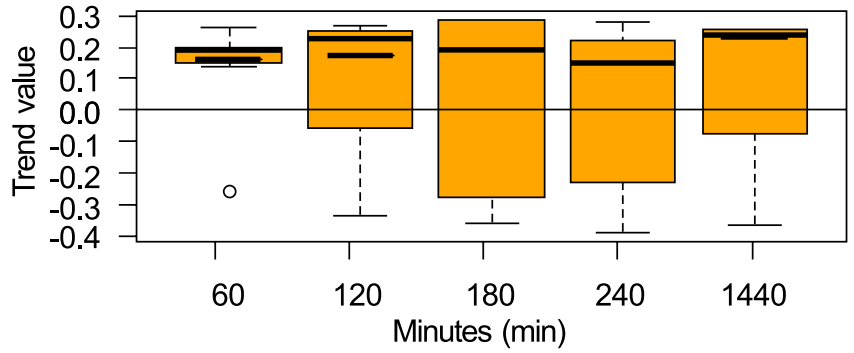

Fig. 6. Trends in precipitation events at the Oravská Lesná (2070-2100).

The next step was to examine only the behavior of the events of the selected simulations. Table 3 presents the trends estimated for all the stations. The highlighted cells represent the significant trends. Most of the long-term trends, regarding both the past and future scenarios, were found to be insignificant. The projected events of the RACMO2.1_ECHAM5 RCM ap- 
Kohnová S. et al.: Detection of future changes in trends and scaling...

$(207-230)$

Table 3. Trends in precipitation events (2070-2100, selected simulations only).

\begin{tabular}{|c|c|c|c|c|c|c|}
\hline \multirow{2}{*}{$\begin{array}{c}\text { Myjava } \\
\text { Simulation }\end{array}$} & \multicolumn{6}{|c|}{ Duration (min) } \\
\hline & Scenario & 60 & 120 & 180 & 240 & 1440 \\
\hline \multirow{3}{*}{ RCA4_ESMLLR } & past & - & - & - & - & - \\
\hline & rcp 45 & - & - & - & - & + \\
\hline & $\operatorname{rcp} 85$ & + & + & + & + & - \\
\hline \multirow{2}{*}{ HadRM3Q0 } & past & NA & - & - & - & - \\
\hline & fut & NA & - & - & - & - \\
\hline \multirow{2}{*}{$\begin{array}{l}\text { RACMO2.1 } \\
\text { ECHAM5 }\end{array}$} & past & - & - & - & - & - \\
\hline & fut & - & - & - & - & - \\
\hline \multirow{3}{*}{ RACMO22E } & past & + & + & + & + & - \\
\hline & $\operatorname{rcp} 45$ & + & - & - & - & - \\
\hline & $\operatorname{rcp} 85$ & + & + & + & + & - \\
\hline Bratislava & Scenario & & & & & \\
\hline \multirow{3}{*}{ RCA4_ESMLLR } & past & - & - & - & - & - \\
\hline & $\operatorname{rcp} 45$ & + & - & + & + & + \\
\hline & $\operatorname{rcp} 85$ & + & + & + & + & - \\
\hline \multirow{2}{*}{$\begin{array}{l}\text { RACMO2.1 } \\
\text { ECHAM5 }\end{array}$} & past & + & + & + & + & + \\
\hline & fut & - & - & - & - & - \\
\hline \multirow{3}{*}{ RACMO22E } & past & - & - & - & - & - \\
\hline & rcp 45 & + & + & + & + & - \\
\hline & $\operatorname{rcp} 85$ & + & + & + & + & + \\
\hline Hurbanovo & Scenario & & & & & \\
\hline \multirow{3}{*}{ RCA4_ESM-LR } & past & - & - & - & - & + \\
\hline & $\operatorname{rcp} 45$ & + & + & + & + & + \\
\hline & $\operatorname{rcp} 85$ & + & + & + & + & + \\
\hline \multirow{2}{*}{$\begin{array}{l}\text { RACMO2.1_- } \\
\text { ECHAM5 }\end{array}$} & past & + & + & + & + & + \\
\hline & fut & - & - & - & - & - \\
\hline \multirow{3}{*}{ RACMO22E } & past & - & - & - & - & - \\
\hline & rcp 45 & + & + & + & + & + \\
\hline & $\operatorname{rcp} 85$ & + & + & + & + & + \\
\hline Oravská Lesná & Scenario & & & & & \\
\hline \multirow{3}{*}{ RCA4_ESMLR } & past & + & + & + & + & + \\
\hline & rcp 45 & - & + & + & - & - \\
\hline & $\operatorname{rcp} 85$ & + & + & + & + & - \\
\hline \multirow{2}{*}{ HadRM3Q0 } & past & NA & + & + & + & - \\
\hline & fut & NA & - & - & - & - \\
\hline \multirow{2}{*}{$\begin{array}{l}\text { RACMO2.1_- } \\
\text { ECHAM5 }\end{array}$} & past & + & + & + & + & + \\
\hline & fut & - & - & - & - & - \\
\hline \multirow{3}{*}{ RACMO22E } & past & - & + & - & - & + \\
\hline & $\operatorname{rcp} 45$ & + & + & + & + & + \\
\hline & rcp 85 & + & + & + & + & + \\
\hline
\end{tabular}

pear to have negative trends at the Myjava, Bratislava and Oravská Lesná stations. On the other hand, future short duration events simulated by the RACMO22E RCM under the worst scenario (rcp8.5) present positive trends 
at the Bratislava and Oravská Lesná stations.

To get a more thorough idea of the behaviour of the future events, we also estimated moving trends in the data. The results from each simulation present either the same or contradictory behaviour. Below we present the moving trends estimated from the projections of each RCM.

The trends estimated at the Myjava and Oravská Lesná stations using projections of RACMO2_ECHAM5 RCM were found to be insignificant for many of the cases. Projections of all the duration events of the same model for the Bratislava station show a tendency to decrease during the first 20 years (Fig. 7). For the Hurbanovo station, long-term negative trends were projected by this model for all the rainfall durations (Fig. 8).

The results of RACMO22E were almost the same for the two scenarios (rcp4.5, 8.5). At the Myjava station a large time period with significant positive trends was detected for all the rainfall durations, except for the daily one, for which the trends were not significant (Fig. 9). The behavior of the results for the Bratislava and Hurbanovo stations were similar to this in Fig. 10. Regarding the Oravská Lesná station, significant trends were only found for the daily rainfall events (Fig. 11).

The trends estimated at the Myjava station using projections from RCA4_ESM-LR for both scenarios were found to be insignificant except for those regarding the 180 and 240-min events, which appear to be negative over the long-term. The majority of trends estimated by this model at the Bratislava station were insignificant. The daily events at the Hurbanovo station projected by RCA4_ESM-LR have a positive tendency for the first 15 years of the period, while the shorter duration events have a tendency to decrease during the first 20 years of the simulation (Fig. 11). The trends found at the Oravská Lesná station were positive during the first 20 years for all the rainfall durations (Fig. 12).

\subsection{Scaling}

For the estimation of the scaling exponents for the future scenario period, we applied a scaling approach based on the scaling of the statistical rainfall moments. The scaling exponents were derived, including all the durations of the rainfall analyzed $(60,120,180,240$ and $1440 \mathrm{~min}$.). The property of the simple scaling of the rainfall intensities in a broad sense is demonstrated be- 


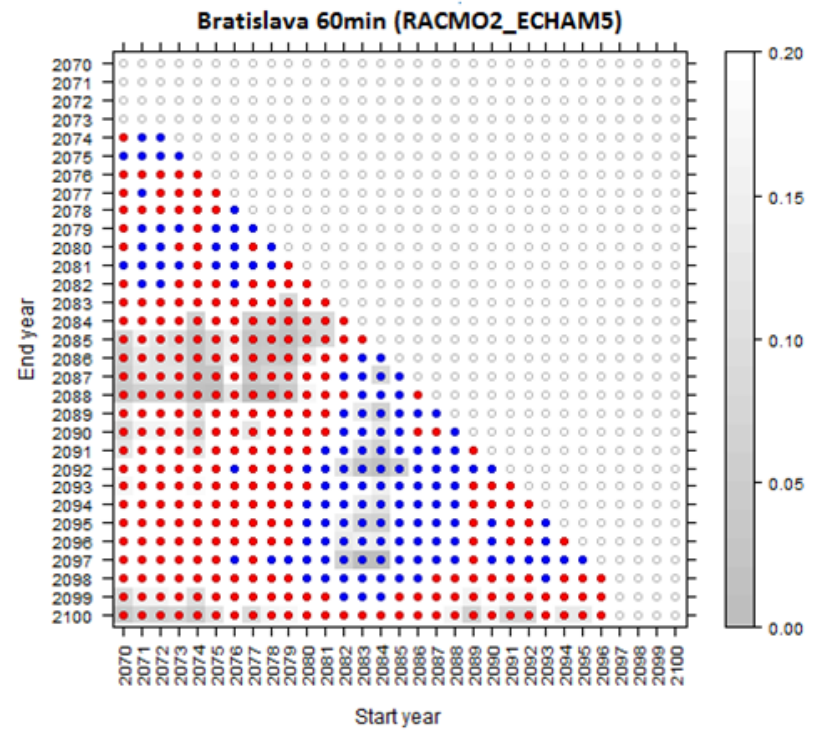

Fig. 7. Moving trends of 60-min projected rainfall at the Bratislava station (RACMO2 _ECHAM5) with significance values (grey colors).

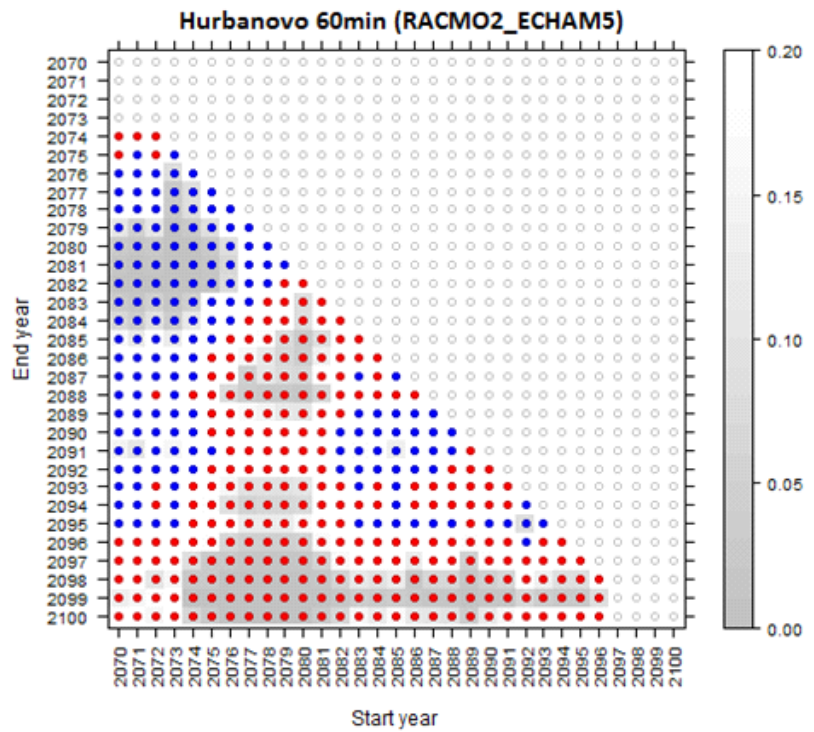

Fig. 8. Moving trends of 60-min projected rainfall at the Hurbanovo station (RACMO2 _ECHAM5) with significance values (grey colors). 


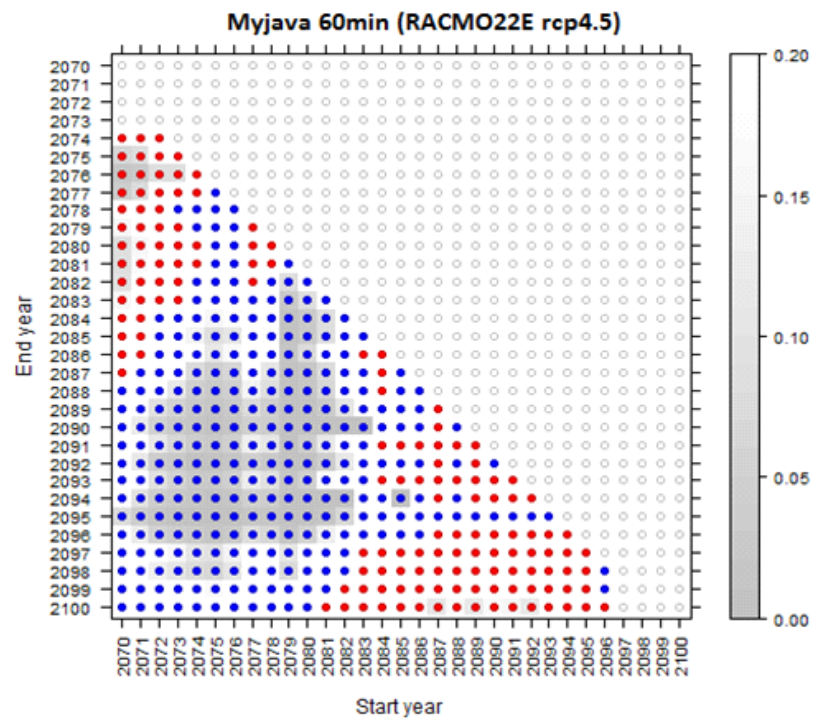

Fig. 9. Moving trends of 60-min projected rainfall at the Myjava station (RACMO22E rcp4.5) with significance values (grey colors).

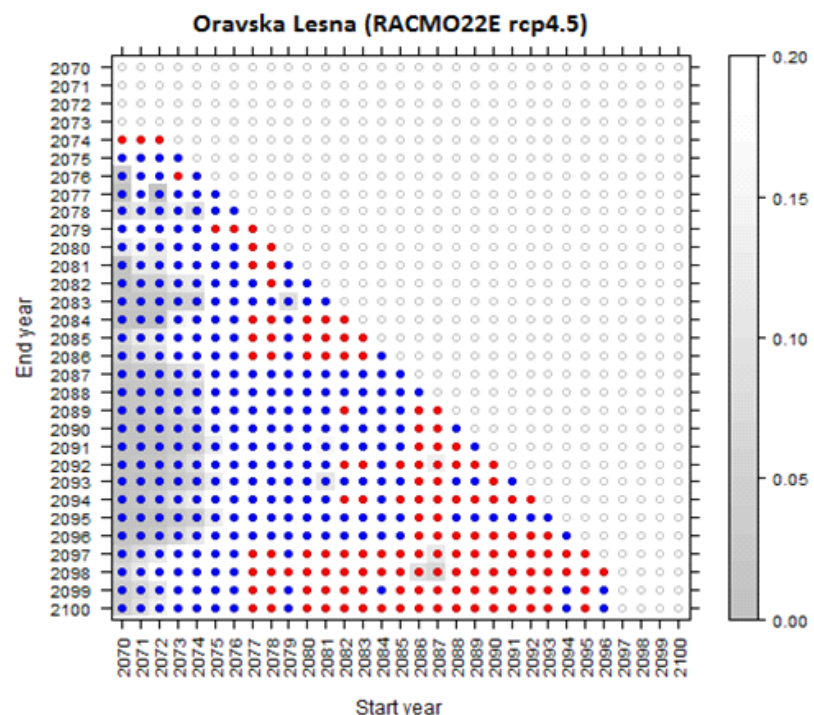

Fig. 10. Moving trends of daily projected rainfall at the Oravská Lesná station (RACMO $22 \mathrm{E}$ rcp4.5) with significance values (grey colors). 


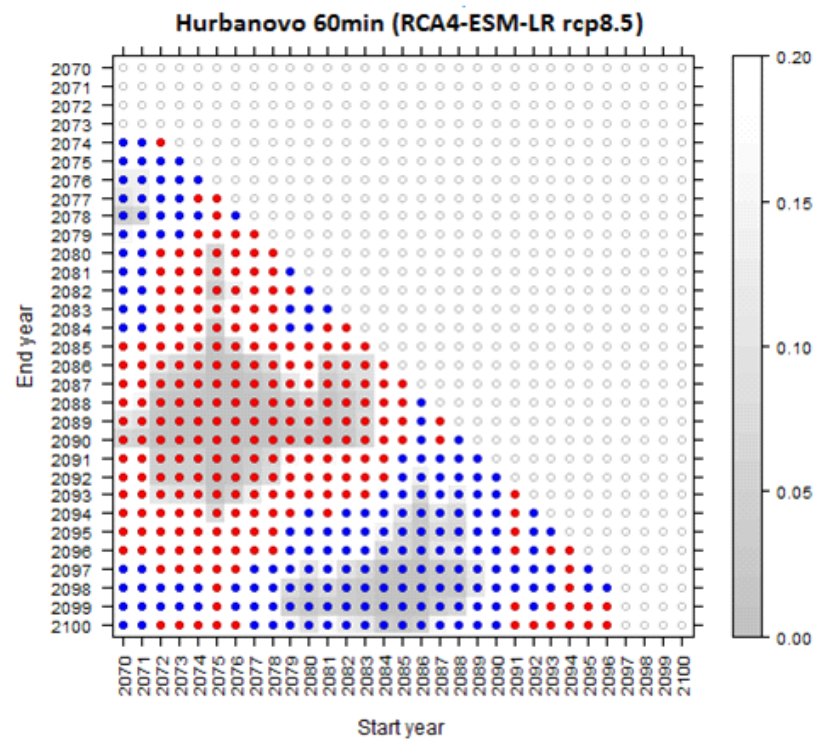

Fig. 11. Moving trends of 60-min projected rainfall at the Hurbanovo station (RCA4ESM-LR rcp8.5) with significance values (grey colors).

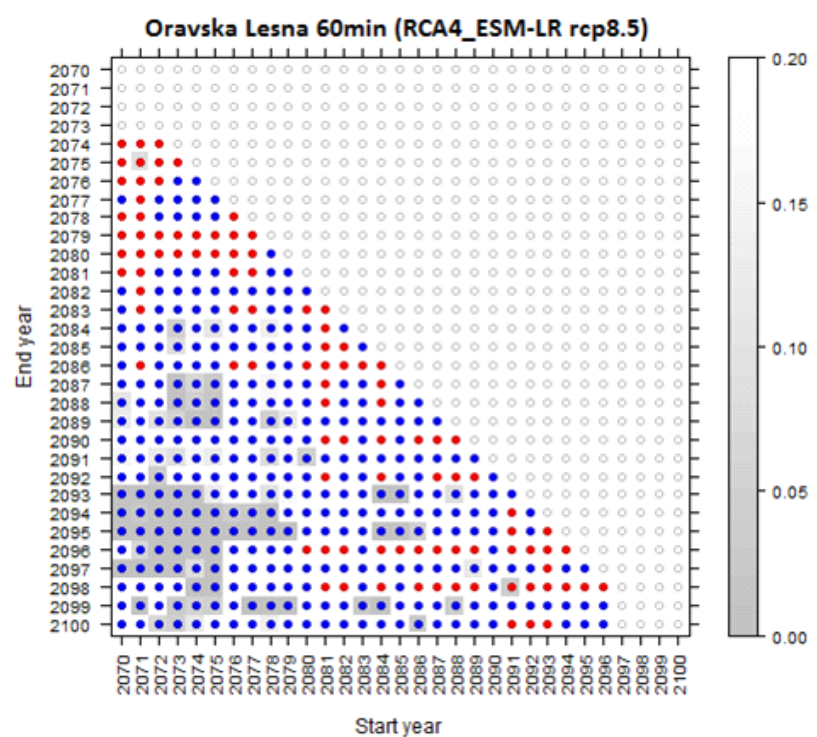

Fig. 12. Moving trends of 60-min projected rainfall at the Oravská Lesná station (RCA4ESM-LR rcp8.5) with significance values (grey colors). 
low using projections from the HadRM-3Q0 simulation. Fig. 13 displays the relationship between the log-transformed values of the moments of various orders versus various rainfall durations at the Myjava station. The scaling exponents of the moments of various orders were estimated as the slopes of the linear regression between these exponents and the rainfall durations.

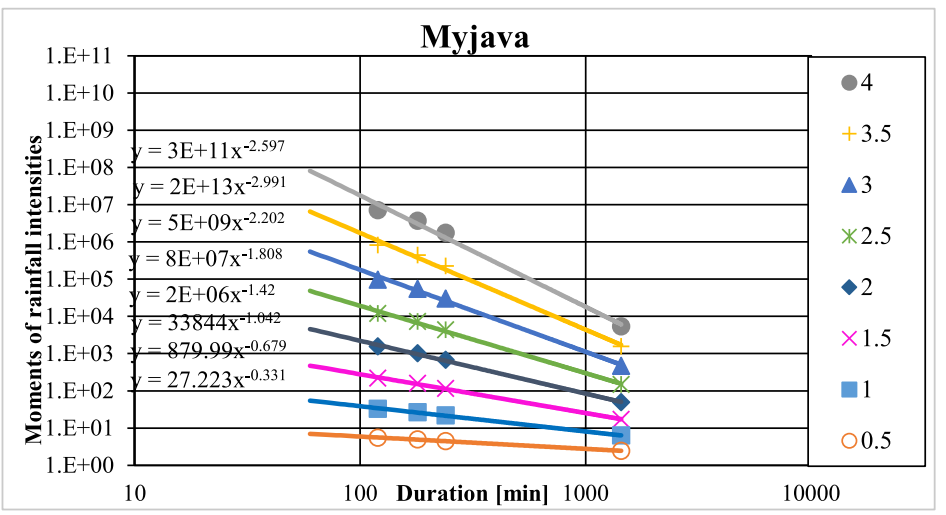

Fig. 13. Log-transformed values of moments of various orders against various rainfall durations at the Myjava station HadRM-3Q0 (SRES A1B) simulation.

Fig. 14 shows the relationship between the scaling exponents of the moments and the order of the moments. The scaling exponents decrease with the order of the moments, and a linear relationship exists between the scaling exponents and the moment orders. These two properties imply that the property of simple scaling in the broad sense exists in the stations analysed.

The same analytic procedure described above was applied to every station using the results of all the scenario simulations selected. The derived scaling exponents are presented in Table 4. The scaling exponents estimated using the results from the selected simulations prevail less than the exponents of the data observed. On the other hand, due to the higher daily precipitation amounts in the future of all the scenarios, the downscaled values of the short-term rainfall in all the stations might be considerably higher in the future horizons. This confirms the very high values of the 100-year design daily precipitation totals estimated for the future horizons using a regional approach, Table 5. For the estimation of the design precipitation values the General Extreme Value Distribution was used as the most appropriate according to the statistical tests. 


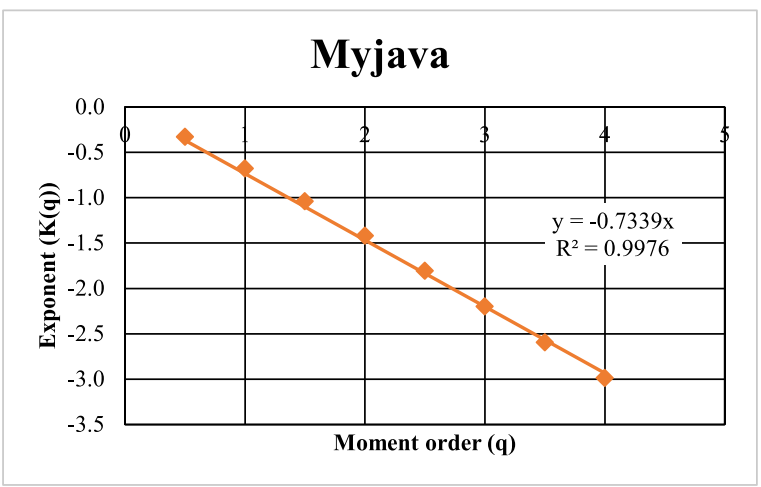

Fig. 14. Relationship between the scaling exponents of the moments and the order of the moments in the stations analysed, HadRM-3Q0 (SRES A1B) simulation at the Myjava station.

Table 4. Summary of derived scaling exponents in the stations analysed for the selected RCM scenarios.

\begin{tabular}{|c|c|c|c|c|}
\hline Scenario / Clim. Station & Bratislava & Myjava & Oravská Lesná & Hurbanovo \\
\hline Observed & 0.7633 & 0.8372 & 0.7292 & 0.7713 \\
\hline HadRM-3Q0 (SRES A1B) & 0.8176 & 0.7339 & 0.5423 & - \\
\hline RACMO22E-rcp4.5 & 0.6694 & 0.6880 & 0.6269 & 0.6773 \\
\hline RACMO22E-rcp8.5 & 0.6791 & 0.5100 & 0.6474 & 0.5490 \\
\hline MAX DIFF & 0.0939 & 0.3272 & 0.1869 & 0.2223 \\
\hline MIN DIFF & 0.0543 & 0.1033 & 0.0818 & 0.094 \\
\hline
\end{tabular}

Table 5. Design 100-year daily rainfall totals for the horizon 2070-2100.

\begin{tabular}{|c|c|c|c|c|}
\hline Scenario / Clim. Station & Bratislava & Myjava & Oravská Lesná & Hurbanovo \\
\hline Observed & 82.6 & 72.9 & 130.0 & 77.0 \\
\hline HadRM-3Q0 (SRES A1B) & 123.9 & 160.6 & 190.4 & - \\
\hline RACMO22E-rcp4.5 & 150.2 & 181.4 & 155.6 & 167.7 \\
\hline RACMO22E-rcp8.5 & 207.5 & 261.5 & 170.8 & 239.3 \\
\hline
\end{tabular}

\section{Discussion}

In this study we estimated the projected changes in the characteristics of the annual maxima short-term rainfall events at four stations in Slovakia: 
Myjava, Bratislava, Hurbanovo and Oravská Lesná. The event characteristics were analyzed for two scenario periods, i.e., one past and one future (1960-2000 and 2070-2100), and compared to the data observed.

According to the changes in the mean characteristics of the 60-min rainfall events, we identified 3 groups of RCM simulations. The greatest part of the RCM simulations (11 out of 23) were identified as simulations with relatively unchanged rainfall intensities and depths. A considerable part of the RCM simulations ( 8 out of 23) show increases in 60-min event depths and intensities. Finally, the $4 \mathrm{RCM}$ simulation showed decreased rainfall intensities and depths. The increases were in general more pronounced in the RCM simulations forced by RCP8.5 compared to the SRES A1B and RCP4.5 scenarios. On the other hand, all the RCM simulations project significant increases, even up to 10 times higher, in daily rainfall intensities and depths. From these results we can deduce that these RCM simulations significantly overestimate daily precipitation events. For comparison, Jacob et al. (2014) found statistically significant increases in total precipitation in large parts of Central Europe for the late 21st century from an ensemble of RCM simulations evaluated on a daily time scale (from the EUROCORDEX and ENSEMBLES projects). The aforementioned changes in detection were only possible for the Hurbanovo station; as for the other stations, the length of the event time-series observed was inadequate.

The uncertainties related to the RCM results are several. There are uncertainties associated with human activities, such as the emissions of greenhouse gases, and the climate system's response to increased greenhouse gas forcing, which includes climate sensitivity and feedbacks. Moreover there are uncertainties that include parameterizations and resolutions as well as initial and boundary conditions inherited from the driving global model, intermodel variability, and issues surrounding the validation or verification of the models. According to Foley (2010), a simulation can never capture the complexities of an actual system. Any numerical model is limited by the knowledge the scientist has about the actual system and the computing resources available to run it. As a result, uncertainty is unavoidable in regional climate scenarios and indeed in any geographical discipline which utilizes numerical modelling.

Kendon et al. (2014) have also shown that the changes derived from models allowing for convection might be considerably different than those from 
a coarser RCM resolution. Several other studies have also demonstrated the better skill of convection-permitting models in reproducing sub-daily precipitation characteristics, including the diurnal cycle and extremes (which are both closely linked to convection). Therefore, the projected changes in precipitation at short temporal scales from the current RCMs have to be interpreted with caution.

\section{Conclusion}

This paper provides a contribution towards the limited knowledge of possible future changes in the characteristics of sub-daily precipitation extremes that are of great importance for hydrological modelling and other applications. We analyzed future heavy rainfall event characteristics projected by an ensemble of Regional Climate Model simulations. The main findings can be summarized as follows:

- at the Hurbanovo station, for most of the RCM simulations the average 60-min event depths and intensities are projected either to increase or to remain constant. On the other hand the depths and intensities of the daily events are projected to increase significantly; in some cases they were found to be ten times larger.

- Trends in future events at the Hurbanovo station were found to be insignificant. At the other stations positive trends in future rainfall events prevailed, except for the daily rainfall at the Myjava station, which shows a negative tendency.

- The scaling exponents estimated using the results from the selected simulations were found to be lower than the exponents of the data observed on average. On the other hand, due to the higher daily precipitation amounts in the future projected by all the scenarios, the downscaled values of the short-term rainfall at all the stations analysed would be considerably higher in the future horizons.

Finally, we can conclude that these findings show a need for recalculating design short-term rainfall for the engineering practice in the future. 
Acknowledgements. This study was supported by the Slovak Research and Development Agency under Contract No. 15-0497 and the Slovak Grant Agency under VEGA Project 1/0710/15.

\section{References}

Bara M., Kohnova S., Gaal L., Szolgay J., Hlavcova K., 2009: Estimation of IDF curves of extreme rainfall by simple scaling in Slovakia. Contributions to Geophysics and Geodesy, 39, 3, 187-206.

Collins M., Booth B., Bhaskaran B., Harris G., Murphy J., Sexton D., Webb M., 2011: Climate model errors, feed-backs and forcings: a comparison of perturbed physics and multi-model ensembles. Clim. Dynam., 36, 9-10, 1737-1766, doi: 10.1007/s00382 -010-0808-0.

Cox D. R., Stuart A., 1955: Some quick sign tests for trend in location and dispersion. Biometrika, 42, 80-95.

Foley A. M., 2010: Uncertainty in regional climate modelling: A review, Progress in Physical Geography, 34, 5, 647-670, 24p.

Gupta V. K., Waymire E. C., 1990: Multiscaling properties of spatial and river flow distributions. Journal of Geophysical Research 95, D3, 1999-2009.

Hamed K. H., Rao A. R., 1998: A modified Mann-Kendall trend test for autocorrelated data. Journal of Hydrology 204, 182-196.

Hlavcova K., Lapin M., Valent P., Szolgay J., Kohnova S., Roncak P., 2015: Estimation of the impact of climate change-induced extreme precipitation events on floods. Contributions to Geophysics and Geodesy, 45, 3, 173-192.

IPCC-TGICA, 2007: "General Guidelines on the Use of Scenario Data for Climate Impact and Adaptation Assessment. Version 2". Prepared by T. R. Carter on behalf of the Intergovernmental Panel on Climate Change, Task Group on Data and Scenario Support for Impact and Climate Assessment, http://www.ipcc-data.org/guide lines/TGICA_guidance_sdciaa_v2_final.pdf.

Jacob D., Petersen J., Eggert B., Alias A., Christensen O. B., Bouwer L. M., Braun A., Colette A., Déqué M., Georgievski G., Georgopoulou E., Gobiet A., Menut L., Nikulin G., Haensler A., Hempelmann N., Jones C., Keuler K., Kovats S., Kröner N., Kotlarski S., Kriegsmann A., Martin E., van Meijgaard E., Moseley C., Pfeifer S., Preuschmann S., Radermacher C., Radtke K., Rechid D, Rounsevell M., Samuelsson P., Somot S., Soussana J. F., Teichmann C., Valentini R., Vautard R., Weber B., Yiou P., 2014: EURO-CORDEX: New high-resolution climate change projections for European impact research. Reg. Environ. Change, 14, 2, 563-578, doi : 10.1007/s10113-013-0499-2.

Kendall M. G., 1955: Rank Correlation Methods. Griffin, London.

Kendon E. J., Roberts N. M., Fowler H. J., Roberts M. J., Chan S. C., Senior C. A., 2014: Heavier summer downpours with climate change revealed by weather forecast resolution model. Nat. Clim. Change, 4, 7, 570-576. 
Koutsoyiannis D., Foufoula-Georgiu E., 1993: A scaling model of storm hyetograph. Water Resour. Res., 29, 7, 2345-2361.

Kupiainen M., Jansson C., Samuelsson P., Jones C., Willén U., Hansson U., Ullerstig A., Wang S., Döscher R., 2014: Rossby Centre regional atmospheric model, RCA4, Rossby Center News Letter, Rossby Centre regional atmospheric model, RCA4.

Lovejoy S., Schertzer D., 1995: Multifractals and rain. In: Kundzewicz Z. W. (Ed.): New uncertainty concepts in hydrology and water resources. UNESCO Series in Water Sciences, Cambridge University Press, New York.

Madsen H., Lawrence D., Lang M., Kjeldsen T. R., 2014: Review of trend analysis and climate change projections of extreme precipitation and floods in Europe. Journal of Hydrology, 519, 3634-3650.

Mann H. B., 1945: Nonparametric tests against trend. Econometrica, 13, 245-259.

Menabde M., Seed A., Pegram G., 1999: A simple scaling model for extreme rainfall. Water Resour. Res., 35, 1, 335-339.

Molnar P., Burlando P., 2008: Variability in the scaling properties of high-resolution precipitation data in the Alpine climate of Switzerland. Water Resources Research, 44, W10404, doi: 10.1029/2007WR006142.

Rummukainen M., 2010: State-of-the-art with regional climate models. Wiley Interdisciplinary Reviews: Climate Change, 1, 1, 82-96.

Samuelsson P., Jones C., Willen U., Ullerstig A., and co-authors, 2011: The Rossby Centre Regional Climate model RCAS3: model description and performance, Tellus, 63A, $4-23$.

van der Linden P., Mitchell J. F. B. (Eds.), 2009: ENSEMLES: climate change and its impacts: summary of research and results from the ENSEMBLES project. Met. Office Hadley Centre, Exeter, UK, 160 p.

van Meijgaard E., van Ulft L. H., van de Berg W. J., Bosveld F. C., van den Hurk B. J. J. M., Lenderink G., Siebesma A. P., 2008: The KNMI regional atmospheric climate model RACMO version 2.1. Koninklijk Nederlands Meteorologisch Instituut.

van Meijgaard E., van Ulft L. H., Lenderink G., de Roode S., Wipfler L., Boers R., Timmermans R. M. A., 2012: Refinement and application of a regional atmospheric model for climate scenario calculations of Western Europe. Tech. rep., KNMI, De Bilt, The Netherlands climate changes Spatial Planning publication: KvR 054/12.

Vasilaki M., Kohnová S., Hanel M., Szolgay J., Hlavčová K., Loukas A., Rončák P., 2017: Detection of future changes in seasonality in extreme short-term rainfall in selected stations of Slovakia. Contributions to Geophysics and Geodesy, 47, 2, 133-148, ISSN 1335-2806.

Veneziano D., Furcolo P., 2002: Multifractality of rainfall and scaling of intensity-durationfrequency curves. Water Resources Research, 38, 12, 1306, doi:10.1029/2001WR 000372.

Yu P.-S., Yang T.-C., Lin C.-S., 2004: Regional rainfall intensity formulas based on scaling property of rainfall. J. Hydrol., 295, 1-4, 108-123. 